\title{
Perceptions of registered nurses regarding factors influencing service delivery in expanding programmes in a primary healthcare setting
}

\begin{abstract}
Authors:
Nnoi A. Xaba ${ }^{1}$

Mapheko D. Peu

Salaminah S. Phiri ${ }^{2}$

Affiliations:

${ }^{1}$ S.G. Lourens Nursing

College, South Africa

${ }^{2}$ Department of Nursing

Science, University of

Pretoria, South Africa

Correspondence to:

Mapheko Peu

Email:

doriccah.peu@up.ac.za

Postal address:

PO Box 667, Pretoria, 0001,

South Africa

Dates:

Received: 14 Jan. 2010

Accepted: 13 July 2012

Published: 22 Nov. 2012

How to cite this article: Xaba, N.A., Peu, M.D. \& Phiri, S.S., 2012, 'Perceptions of registered nurses regarding factors influencing service delivery in expanding programmes in a primary healthcare setting', Health SA Gesondheid 17(1), Art. \#535, 12 pages. http://dx.doi. org/10.4102/hsag.v17i1.535
\end{abstract}

(C) 2012. The Authors. Licensee: AOSIS OpenJournals. This work is licensed under the Creative Commons Attribution License.
The aim of this study was to explore and describe the perceptions of registered nurses regarding factors influencing service delivery regarding expansion programmes in a primary healthcare setting, using a qualitative approach. The registered nurses, who have been working in the clinics for more than two years and have been exposed to the expansion programmes there, were purposively sampled. Two focus group interviews were conducted in a neutral place and the data collected by the researcher Nnoi A. Xaba (N.A.X.). Data were analysed by the researcher and an independent co-coder using the Tesch method. Categories, subcategories and themes were identified; those that formed the basis of discussion were disabling factors, enabling factors, client-related factors, service-related factors and solutions to problems. It is recommended that integration of programmes and coordination be done at a provincial level and planned together with the training centres in order to alleviate problems in service delivery. Training on expansion programmes in the form of in-service education should be carried out continually in the region.

Die doel van die studie was om die persepsie van geregistreerde verpleegkundiges met betrekking tot die faktore wat dienslewering van die uitbreidingsprogramme in ' $n$ primêre gesondheid opset beinvloed; te eksploreer en te beskryf. ' $n$ Kwalitatiewe benadering is gevolg in die iutvoering van die studie. 'n Doelgerigte steekproef is uitgevoer vanuit geregistreerde verpleegkundiges wat vir langer as twee jaar in die klinieke werksaam was en blootgestel is aan die uitbreiding programme. Twee fokus groep onderhoude is deur die navorser Nnoi A. Xaba (N.A.X.) in 'n neutrale opset uitgevoer. Data is deur die navorser en 'n onafhanklike kodeerder ontleed volgens Tesch se metode van analise. Kategorieë, sub-kategorieë en temas was geidentifiseer. Die kategorieë fundamenteel tot die bespreking behels: remmende faktore, bydraende faktore, kliënt-verwante faktore, diens-verwante faktore, en oplossing van probleme. Daar word aanbeveel dat die integrasie en koordinasie van programme op provisiale vlak beplan word in samewerking met opleidings instansies om die dienslewerings probleem te verlig. In die streek behoort opleiding met betrekking tot die uitbreidingsprogramme deurlopend deur middel van indiensopleiding gedoen word.

\section{Introduction}

Since 1994 the transformation process within the healthcare system in South Africa has expanded. Major challenges lay in overcoming the problems of implementation (Kenyon, Heywood \& Conway 2002:203). One of the priorities identified was the expansion of programmes in the delivery of primary healthcare (PHC) services. The district healthcare system was introduced as a vehicle to drive the PHC approach, based on comprehensive PHC (African National Congress 1994:19-20; Department of Health (DoH) 1996:6). Over the past five years the number of clients has escalated, affecting the progress of expansion of services in the PHC setting (Gauteng DoH 2004-2006:70). Multiple factors such as equipment, structure, marketing and staff shortages were identified as impacting on service delivery (Rall \& Meyer 2006:11; Muller 2000:63). The problem of poor service delivery still exists, despite the fact that some of these factors have been attended to. Van Rensburg (2004:446) also documented factors that lead to poor service delivery in both rural and urban areas.

\section{Problem statement}

The Gauteng DoH introduced a document on the Service Implementation Plan (SIP) to ensure a phased decentralisation of services and resources, which was linked to the expansion programmes (Gauteng DoH 2004-2006:70). On observation, the researcher Nnoi A. Xaba (N.A.X.) identified 
some factors linked to poor service delivery which were similar to those identified by Heunis, Van Rensburg and Classen (2006:44), such as inadequate staff and a shortage of resources. These factors were impacting on the quality of service delivery and were experienced differently by the PHC nurses, resulting in different perceptions as experienced and interpreted by different people. The researcher observed that the registered nurses were directly involved with the expansion programmes. There was hence a need to explore and describe the perceptions of registered nurses regarding factors affecting service delivery in respect of the expansion programmes in a PHC setting.

\section{Background of the study}

Healthcare delivery in South Africa has been facing challenges related to the expansion of programmes in PHC service delivery, to combat the changing community profile and strengthen existing services (DoH 1996:3). The need to restructure the health system increased over time, and the burden on healthcare services increased due to a rapid rise in the incidence of human immunodeficiency virus, acquired immunodeficiency syndrome and other chronic diseases (DoH 1996:5).

The principle of universal access to health care, as discussed by the DoH (1996:7), implies that all financial, geographical and/or other barriers should be addressed. This study examined perceptions of registered nurses as to factors that influence service delivery regarding the expansion of programmes in a PHC setting.

In the restructuring of the healthcare system in 1994 a model for service delivery was introduced to enable provision of PHC services (Modiba, Gilson \& Schneider 2001:188; Gauteng DoH 2004-2006:53). The PHC package outlined comprehensive services and specific norms and standards (DoH 2001). The services identified are in line with the basic elements of PHC and the clinics serve as a point of entry into the healthcare system (Dennill, King \& Swanepoel 1999:3).

Commitment to the PHC approach was confirmed at a conference on health promotion in Ottawa in 1986 (Hattingh, Dreyer \& Roos 2006:53). In Gauteng the SIP guides delivery of services to ensure sustainability and cost containment (Gauteng DoH 2004-2006:68). The SIP ensures that the expansion of programmes and services is implemented in the districts in phases. Further challenges and constraints to services were identified in a study conducted in Limpopo (Netshandane, Nemathaga \& Shai-Mahoko 2005:59). Heunis et al. (2006:43) and Mashego and Peltzer (2005:13) also revealed that gaps were related to limitations in the facilities, which failed to offer the full spectrum of the PHC package. This made the researcher keen to explore the perceptions of PHC nurses regarding these factors. The following question guided the study: What are the perceptions of registered nurses regarding factors influencing service delivery in expanding programmes in a PHC setting?

\section{Objective of the study}

The following objective guided the process of research: To explore and describe the perceptions of registered nurses regarding factors influencing service delivery in expanding programmes in a PHC setting.

\section{Definition of key concepts}

PHC: It is essential health care made available, affordable and universally accessible to individuals and families in the community by means acceptable to them through their full participation and at a cost that the community can afford (De Haan, Dennill \& Vasuthevan 2005:10).

Service delivery: The day-to-day provision of health care to individuals, families and the community at a PHC clinic. The SIP guided delivery of services in order to ensure sustainability and cost containment (Gauteng DoH 2004-2006:68).

Expansion programmes: In this study these refer to programmes introduced with implementation of the SIP in Gauteng Province as part of the integrated management of child illness (IMCI) and prevention of mother-to-child transmission (PMTCT).

PHC setting: In this study this refers to clinics in Region C that are offering a comprehensive healthcare service. The Gauteng Province consists of three regions, Regions A, B and $C$, with Region $C$ further divided into the Tshwane and Metsweding Districts in the Pretoria area and sub-districts.

Perception: The Concise Oxford English Dictionary of Current English explains this as the ability to refer sensory information to an external object, giving meaning to what a person experiences in life (Allen 1990:883).

\section{Significance of the study}

It is anticipated that the study will contribute to identification of factors affecting service delivery, with the aim of improving the quality of health care in the expansion programmes, and also add to the body of knowledge in PHC service delivery.

\section{Research method and design Design}

The study followed a qualitative approach and focused on exploring and describing the perceptions of registered nurses regarding factors affecting service delivery. This was used to describe experiences of phenomena and perceptions and to understand the meaning of the perceptions (Brink, Van Der Walt \& Van Rensburg 2006:113). Through qualitative enquiry the registered nurses` perceptions, assumptions, judgements, fears and suppositions were discussed in the context of their working experiences, and first-hand information was obtained. This approach was used to enable the researcher to explore and describe factors as they impact on service delivery. 


\section{Population and sampling}

The population consisted of registered nurses involved in delivery of PHC services daily, who have been involved directly or indirectly in the expansion programme. The sample in this study was selected through purposive sampling, which was based on the belief that the researcher's knowledge about the population could be of help in handpicking the participants. Purposive sampling was used to ensure that those participants who had the best experience of the expansion programmes in IMCI and HIV programmes were included.

Inclusion criteria were registration with the South African Nursing Council as a registered nurse, with two years of exposure in the PHC setting. Two Community Health Centres from Region $C$ were utilised as venues for the focus groups from two sub-districts, one from each sub-district where the expansion of programmes had been implemented. Participants were purposively selected from the clinics in the two sub-districts in the Tshwane District, and had to be directly or indirectly involved as managers with the expansion programmes. The two venues for conducting the focus group interviews were chosen because they were central to the participants in the two groups and easily accessible.

\section{Data collection}

The focus group interview was utilised as a data collection method. Data collection and analysis were conducted simultaneously, with analysis occurring after each focus group interview. A total of two focus group interviews were conducted with registered nurses in a PHC setting in two separate Community Health Centres in the region. Saturation was reached with the second focus group, and the number of focus interviews depended on the saturation of information. Each focus group consisted of 10 participants selected purposively from identified clinics in the two subdistricts and those who met the inclusion criteria.

The researcher conducted the two focus group interviews with the help of a second facilitator. A tape-recorder was used for more comprehensive record-keeping. Field notes were also collected. The two interview sessions were conducted on different dates because the participants were not all available on the same day and the venues were in different subdistricts. The diverse key informants, such as coordinators of the IMCI, Expanded Programme on Immunisation (EPI) and HIV and AIDS programmes were interviewed on the same research question. Facilitation skills used during the focus group interview included probing, reflection, clarification, listening and paraphrasing. Probing persuaded participants to give more information about the issue under study (De Vos, Strydom, Fouche \& Delport 2005:290). Saturation was reached when the themes and categories in the data became repetitive and redundant, such that no new information was collected (De Vos et al. 2005:306; Polit \& Beck 2006:59).

\section{Data analysis}

The analysis followed an analytical circle with some of the generic steps overlapping, since they only served as guidelines (De Vos et al. 2005:334). The steps of data analysis were followed as described by Tesch (1990) in Creswell (1994:154). The researcher started by repeatedly listening to the tape and transcribing all the information verbatim onto a script. The researcher then read through all the transcripts and the field notes in order to obtain the meaning.

Ideas and topics were listed which matched the content. Topics were organised into columns and similarities were clustered. Clusters were then abbreviated into codes and categories were formed. Categories, subcategories and themes were identified and controlled by comparing with literature. The researcher was involved in the analysis together with the independent coder.

\section{Ethical considerations}

Ethical approval was obtained from the University of Pretoria's Ethical Committee (Ethical clearance No. S110/2007). Permission to conduct the study was obtained from the Gauteng DoH and Region C Director and clinic managers in the two respective clinics (Cormack 2000:130). The participants were afforded the right to fair treatment and the right to privacy as the discussion took place in a private room. The participants gave written consent and were assured of their freedom from harm when the researcher gave an explanation of the study. The researcher also explained to the participants their right to withdraw from the study at any time without being punished (Polit \& Hungler 1995:119).

Extra precautions were taken to safeguard the participants with regard to anonymity; their names were not mentioned during the discussion, even if anonymity is rarely possible with a focus group of 10 people because of the presence of other participants. Information regarding the sex and age of the participants was withheld (Polit \& Beck 2006:91). The researcher also ensured that no form of deception was inflicted on the participants by explaining the topic and the process of data collection to them and obtaining a consent form from all. The results of the study were made available to participants (Polit \& Beck 2006:125).

\section{Trustworthiness}

Lincoln and Guba (1985:290) describe trustworthiness as the ability of the researcher to persuade the audience that the findings of the study are worth paying attention to. Lincoln and Guba (1985), as cited in Polit and Beck (2006:332), recommend the following criteria for establishing the trustworthiness of qualitative data: credibility, dependability, confirmability and transferability. These criteria were met in this study (Table 1).

\section{Discussion of results and literature control}

Data from the two focus interview transcripts was grouped into five main categories: disabling factors, enabling factors, 
TABLE 1: Four measures of trustworthiness.

\begin{tabular}{|c|c|c|}
\hline Strategy & Criteria & Techniques used \\
\hline \multirow[t]{8}{*}{ Credibility } & Prolonged engagement & Sufficient time invested data collection during the interview \\
\hline & & Participants visited after data collection; researcher spent a day in their clinics to clear misinformation and build trust \\
\hline & Persistent observation & $\begin{array}{l}\text { A day spent at the clinic working in some of the programmes (e.g. IMCI, TB, HIV and AIDS) with the nurses in order to } \\
\text { continue observation during data analysis }\end{array}$ \\
\hline & External checks & $\begin{array}{l}\text { Peer debriefing: The researcher consulted with programme managers and experts in qualitative research and aspects of } \\
\text { research to discuss the findings }\end{array}$ \\
\hline & & $\begin{array}{l}\text { Member check: The researcher internally solicited the reaction of participants by availing them of preliminary findings and } \\
\text { interpretations of the study }\end{array}$ \\
\hline & Researcher credibility & The researcher was trained in interviewing and research \\
\hline & & Information about the researcher's credentials and personal connection with the topic and population studied was revealed \\
\hline & Data source triangulation & The researcher interviewed programme coordinators in the regional office during data analysis to triangulate data \\
\hline Dependability & Inquiry audit & $\begin{array}{l}\text { The interview and tape transcripts were scrutinised by the external reviewer and the supervisor who is an expert in } \\
\text { qualitative studies }\end{array}$ \\
\hline \multirow[t]{2}{*}{ Confirmability } & Audit trial & The investigator in the inquiry audit developed an audit trial consisting of transcripts and tapes \\
\hline & & $\begin{array}{l}\text { The transcripts and tape were handed to the expert in supervising qualitative studies, to conduct an enquiry audit on the } \\
\text { meaning of the data }\end{array}$ \\
\hline Transferability & & The researcher showed the findings to the programme managers in the clinics to check for congruency in the information \\
\hline
\end{tabular}

Source: De Vos et al. (2005:345-7); Polit \& Beck (2006:332-3); Welman, Kruger and Mitchell 2005:362-363) (modified)

client-related factors, service-related factors and solutions to problems. These were further divided into subcategories. Themes were identified and developed to substantiate each subcategory. A summary of the categories, subcategories and themes is provided (Table 2).

\section{Disabling factors}

The disabling factors emerged as the first category, and the following subcategories were identified: time limitations, budgetary constraints, infrastructural problems and inadequate skills.

\section{Time limitations}

The following themes emerged Lack of extended hours for some programmes for tuberculosis (TB) and antiretroviral treatment (ART) services; family planning services not available after-hours for learners and workers; and statistical errors occurring with records because clients who came during weekends and after-hours were not properly recorded. The participants indicated that some of the priority programmes were not accessible to all clients, including learners, despite the fact that the service hours had been extended. This was expressed as follows:

'We are a 24-hour health service but some programmes are not covered in the 24-hour service'.

'Clients who came after-hours or during the weekends requesting TB or ART services are turned away and given another time.' (Majority of Participants, Females/Registered nurses/Ages of service varied from 6-30 yrs)

The PHC package sets out the norms for service delivery, one of which is that PHC facilities should serve as a 'onestop' provider of health care, for a minimum of eight hours per day, five days a week (DoH 2001:12). The expansion of programmes in relation to time included making these services available to working people after-hours, as well as provision of emergency maternity services 24 hours a day (Hattingh et al. 2006:65).

The availability of services entails that they should be open at the time that they are needed. Availability also means that services should be functionally accessible to people who work office hours. According to the Gauteng DoH (20042006:52) the hours in many clinics have been extended to ensure accessibility and availability during working hours as well as after-hours. The study also showed that people who work office hours had no access to public PHC services, as some clinics continued to schedule certain services on certain days (Meyer, Heunis, Janse van Rensburg-Bonthuyzen, Engelbrecht \& Summerton 2003:9; Mashego \& Peltzer 2005:18).

\section{Budgetary constraints}

The participants identified the following themes here: limited funds, need for more stock, escalating client numbers, and not all services can be rendered in some clinics. These were expressed as follows:

'Patient turnover exceeds our budget ... and the stock of supplies and pharmacy is strained'.

'I have been to some of these MOU [maternal obstetric unit] facilities, the physical structure does not accommodate them, and they are small'.

'Yes in the clinic there are structural problems ... some clinics are very small and we cannot render all required services.' (Few Participants, Females/Registered nurses/Ages on experience ranged from 6-30 years)

The participants perceived that because of limited resources, which affected the availability of space, some programmes could not be introduced in certain clinics. The Gauteng DoH Strategic Plan 2004-2006 indicates that the transformation and implementation of the PHC package have an impact on the budget (Gauteng DoH 2004-2006:69), since it had to occur within the existing resources of the public sector. Studies conducted on the perceptions of nursing managers revealed that without proper structures it is difficult to function effectively, especially during the transformation period. It was also revealed that inadequate resources were a contributory factor to ineffective management and shortages of equipment (Buys \& Muller 2000:53; Peltzer, Skinner, Mfecane, Shisana, Nqeketo, Mosala et al. 2005:30). 


\section{Infrastructural problems}

Here the following three themes were identified: lack of space for different programmes in a clinic, close proximity of some clinics to the hospital, and lack of equipment. The participants indicated the need for privacy and a waiting area, especially if the 'supermarket approach' was to be used, and introduction of IMCI, PMTCT, and voluntary counselling and testing (VCT). This was expressed as follows:

TABLE 2: Data analysis of focus interviews.

\begin{tabular}{|c|c|c|}
\hline Category & Subcategory & Themes \\
\hline \multirow[t]{12}{*}{ Disabling factors } & \multirow[t]{2}{*}{ Time limitations } & Lack of extended hours for some programmes for TB and ART services \\
\hline & & Family planning services not available after-hours for learners and workers \\
\hline & \multirow[t]{4}{*}{ Budgetary constraints } & Limited funds affected \\
\hline & & Need for more stock \\
\hline & & Escalating client numbers affecting quality of care and nurse-client ratio. \\
\hline & & Not all programmes can be rendered in some clinics \\
\hline & \multirow[t]{4}{*}{ Infrastructural problems } & Lack of space for different programmes in a clinic \\
\hline & & Small buildings \\
\hline & & Close proximity of some clinics to the hospital \\
\hline & & Lack of equipment \\
\hline & \multirow[t]{2}{*}{ Inadequate skills } & Shortage of doctors and physiotherapists \\
\hline & & Training in short courses is expensive \\
\hline \multirow[t]{5}{*}{ Enabling factors } & \multirow[t]{2}{*}{ Integration of $\mathrm{IMCl}$ into $\mathrm{PHC}$} & Positive improvement in care of children under five years old \\
\hline & & Integration of IMCl into other services positive \\
\hline & Utilisation of IMCI nurses & $\mathrm{IMCl}$ nurses utilised for other programmes, such as ANC and PNC \\
\hline & for programmes & \\
\hline & NGOs' contribution & Caregivers trained and funded by NGOs help with home-based care \\
\hline \multirow[t]{11}{*}{ Client-related factors } & \multirow[t]{2}{*}{ Client service preferences } & Stereotypes in certain clinics because of time factors and staff attitudes \\
\hline & & Cross-border issue increasing workload \\
\hline & \multirow[t]{4}{*}{ Service duplication } & Client shopping around for diagnosis \\
\hline & & Clients misuse services due to denial and stigma \\
\hline & & Clients not revealing their status and ending up having two files in one clinic \\
\hline & & Clients using wrong addresses making follow-up difficult \\
\hline & Scramble for free service & Foreigners utilising the free services \\
\hline & Client selling medicines & TB-positive clients selling positive sputum as a way of enabling others to get a social grant \\
\hline & \multirow[t]{3}{*}{ Poor adherence to PMTCT } & HIV-positive clients on PMTCT not complying with using infant formula \\
\hline & & Confidentiality and stigmatisation are problems \\
\hline & & Family and community cultural practices and queries on breast-feeding \\
\hline \multirow[t]{5}{*}{ Service-related factors } & Involvement of health promoters & Involvement of health promoters affecting trust and confidentiality \\
\hline & \multirow[t]{2}{*}{ Competing of programmes } & Programmes such as EPI and IMCI not regarded as important \\
\hline & & HIV and AIDS given first preference \\
\hline & Lack of continuity of care & Clients moving from one clinic to another \\
\hline & Lack of security in clinics & Security breaches by clients \\
\hline \multirow[t]{13}{*}{ Solution of problems } & Need to integrate services & Integration of HIV and AIDS and mother and child services \\
\hline & \multirow{7}{*}{$\begin{array}{l}\text { Need for electronic } \\
\text { record-keeping }\end{array}$} & To manage extreme drug-resistant TB \\
\hline & & The use of technology in MOUs for fetal monitoring \\
\hline & & To prevent patients from having more than one file in one clinic \\
\hline & & Use of ID numbers in clinics \\
\hline & & To control drugs issued to clients to avoid double collection in one month in different clinics \\
\hline & & To fast-track the management of clients in different expansion programmes \\
\hline & & To curb health facility shopping by clients \\
\hline & Strengthening support groups & Strengthening available support groups to include nutrition and expansion programmes \\
\hline & \multirow[t]{3}{*}{ Healthcare worker training } & Upgrading the training of older nurses on expansion programmes on a continual basis \\
\hline & & More training on expansion programmes to allow rotation of staff \\
\hline & & More nurses to be trained in primary mental health \\
\hline & Community education & $\begin{array}{l}\text { The use of clinic committee members to educate the community on health service operational } \\
\text { issues and create awareness of available services }\end{array}$ \\
\hline
\end{tabular}


'You must have space to render programmes like IMCI and PMTCT, maybe we need a waiting area for these people and privacy for VCT.'

'You might also need space to offer procedures such as drawing of blood.' (Three Participants, Females/Registered nurses/Ages on experience ranged from 6-30 years)

The participants also expressed that there was a lack of electronic equipment in some maternal obstetric units, such as Doptones used to monitor the fetal heartbeat during labour, which is very important. The objective of the Gauteng DoH Strategic Plan 2004-2006 was to reduce the backlog of infrastructure and equipment and ensure that construction, rehabilitation, upgrading and maintenance of infrastructure were linked to the SIP (Gauteng DoH 2004-2006:215). This entire plan was linked to the budget.

The study revealed that a lack of provision of infrastructure in some clinics hampered service delivery, and also issues such as frequent breakdowns, lack of transport for patients and lack of telephones. The health providers also confirmed that lack of space grossly affected the quality of care (Ijumba 2002:195). Heunis et al. (2006:44) also state that some clinics are not designed for provision of a PHC package. As a result some equipment, such as examination lights, were in short supply in many facilities, whilst in other cases the maintenance of equipment was poor. Another study conducted in Limpopo Province on the community's perceptions of quality of healthcare services revealed that small buildings were inadequate to provide a good service (Mashego \& Peltzer 2005:18).

\section{Inadequate skills}

Here the participants universally perceived that there was a shortage of skills because of the 'brain drain'. Despite training for expanded programmes having been conducted in the region, the shortage was still experienced for professions such as doctors and physiotherapists. Clinics were left with newly qualified nurses who still needed to be upgraded on certain skills. The participants also indicated that some training, like that for IMCI, had to be cancelled because of a shortage of doctors to do the clinical accompaniment:

'Highly experienced nurses leave the country and with this age we really experience that drainage of nurses, doctors and physiotherapists'.

'Again lack of skills by the professional nurses because some of the short courses are expensive and people cannot afford.' (Two Participants, Females/Registered nurses/Ages on experience ranged from 6-30 years)

Healthcare providers should be appropriately qualified and not be expected to render services that are not applicable to their level of training (Hattingh et al. 2006:65). One of the key challenges reported in the Gauteng DoH Strategic Plan 2004-2006 was retention of highly skilled and scarceskilled professionals in the public sector, including specialist nurses and emergency care personnel (Gauteng DoH 2004-2006:198).

The Gauteng DoH Strategic Plan 2004-2006 further confirmed that one of the constraining factors was a shortage of qualified PHC nurses due to their inability to release staff for long periods of training. Lengthy procurement procedures were also identified as hindering courses being efficiently and timeously conducted (Gauteng DoH 2004-2006:201; Ijumba (2002:183). Inadequate skills were also reported by Heunis et al. (2006:44) in their study on assessment of the implementation of the PHC package. The study also revealed lack of training in most of the programmes being expanded. In some places only one nurse could be trained in a specific programme, resulting in a gap in service delivery when she orhe was absent or on leave (ibid.).

The issue of in-service training being planned and number of programmes in existence also impacted on service delivery. This was voiced by managers, who felt that they were burdened by multiple and conflicting demands for in-service training from the different programmes, such as TB, HIV and AIDS and PMTCT. All of these placed a burden on service delivery (Leon, Bhunu \& Kenyon 2002:217).

\section{Enabling factors}

The second category that was formulated was called enabling factors, and the three subcategories that emerged here were the integration of IMCI into PHC, the utilisation of IMCItrained nurses for programmes, and the contribution from non-governmental organisations (NGOs).

\section{Integration of IMCl into PHC}

The following themes emerged here: positive improvement in the care of children under the age of five years, and integration of IMCI into other services such as PMTCT. This was expressed as follows:

'Integration of IMCI is like if a child comes for IMCI brought by mother, the sister will immediately check for immunisation and be referred, even in antenatal care, also it is important to integrate'.

'I think the integration with other services is very important because if they are isolated it poses a problem.' (Few Participants, Females/Registered nurses/Ages on experience ranged from 6-30 years)

The IMCI strategy was developed by the World Health Organisation (WHO) and United Nations Children's Fund (UNICEF) in 1995 and adopted by South Africa in 1996. IMCI offers a set of interventions that promote the rapid recognition and effective treatment of the major killer diseases amongst children younger than five years (WHO \& UNICEF 2003:7).

\section{Utilisation of IMCI nurses for programmes}

The participants indicated that nurses trained for IMCI were being utilised for specific programmes, such as antenatal care (ANC) and postnatal care (PNC), which was viewed as an enabling factor and expressed as follows:

'Yes we have specific nurses allocated to specific programmes, in IMCI sometimes you will be allocated to do ANC and sometimes you do PNC and this is an enabling factor.' (Majority of Participants, Females/Registered nurses/Ages of experience ranged from $6-30$ years)

Heunis et al. (2006:44) stated that nurses should be trained in numerous key programmes in order to be able to implement 
the PHC package effectively. Studies have revealed that the shortage of nurses in these programmes will impact on the quality of care, whilst the effectiveness of these programmes depends on optimal utilisation of the available human resources (Buys \& Muller 2000:53; Hattingh et al. 2006:115).

\section{NGO contribution}

The participants acknowledged that NGOs were really helping and were of great assistance in the ART and home-based care services, but had problems with funding. Caregivers were trained comprehensively by NGOs and were serving large parts of the community. This was expressed as follows:

'The NGO used to help but now they have not been funded and they were not paid and now the caregivers feel very demotivated'.

'With regard to poverty, the NGOs are helping some clients and this improves compliance.'(Six Participants, Females/Registered nurses/Ages of experience ranged between 6-30 years of experience)

The Gauteng DoH Strategic Plan 2004-2006 explains that volunteerism is being promoted, specifically through the use of community healthcare workers for community-based programmes and health promotion services (Gauteng DoH 2004-2006:54). The report also confirms that NGOs are being supported in implementing outreach programmes related to the programmes being expanded in an integrated manner (Gauteng DoH 2004-2006:54). The main role of NGOs is to contribute to the improvement of the quality of care in the communities and families (Uys \& Cameron 2003:6).

\section{Client-related factors}

Five subcategories emerged here: client service preferences, service duplication, scramble for free services, client entrepreneurship with services and poor adherence to PMTCT.

\section{Client service preferences}

In this subcategory two themes emerged as a stereotype of certain clinics because of time factors and staff attitudes, with cross-border issues increasing the workload of staff. This was expressed as follows:

'We have a problem of people leaving clinics near their homes to overcrowd our clinics because they believe that the service here is better'.

'They say they have problems with the attitudes of the staff in their clinics.' (Majority of Participants, Females/Registered nurses/Ages on experience ranged from 6-30 years)

The Bill of Rights enshrines clients' right to freedom of movement and right to choice in life (Hattingh et al. 2006:67). Clients can therefore not be denied treatment because of their preferences. Overcrowded PHC facilities are uncomfortable for both clients and healthcare workers, and therefore need to be corrected (Hattingh et al. 2006:66). Peltzer et al. (2005:30) state that the district boundaries for PHC delivery are coterminus with political boundaries. This means that people living in a particular health district are expected to obtain health services within their boundaries.

\section{Service duplication}

Here the following themes emerged: clients shopping around for a diagnosis, clients' misuse of services due to denial and stigma, clients not revealing their status and ending up having two files in one clinic, and clients using wrong addresses which made follow-up difficult. The participants perceived that because of the close proximity of the villages and the clinics, and because of the availability of public transport in their areas, clients (especially VCT and HIV-positive clients) had a tendency to 'shop around'. They felt that clients would go around to several clinics, shopping around for a diagnosis, and that this contributed to increased workloads and shortages of staff:

'Clients misuse the services ... the VCT patients move from one clinic to another to test, seeking for a better diagnosis'.

'Denial makes them not to believe that they have tested HIV positive ... they want to confirm the diagnosis elsewhere'.

'Particularly with the clients who are HIV positive, because of stigma, they feel that if they go to a facility where they are not known, they feel better, to hide their status and this shows that they are in denial.'(Majority of Participants, Females/Registered nurses / Ages of experience ranged from 6-30 years)

A health survey conducted on the responses of individual people to their HIV status revealed different reactions, ranging from anger, suicide and denial to fear of death. The respondents explained that clients presented themselves several times for HIV testing, hoping that things might change. Such behaviour was related to denial of the diagnosis (Modiba et al. 2001:191; Botma, Motiki \& Viljoen 2007:48; Peltzer et al. 2005:29; Shapiro, Lockman, Thior, Stocking, Kebarabetswe, Wester, et al. 2003:221; Greeff \& Phetlhu 2007:13).

\section{Scramble for free services}

In this subcategory participants expressed their view that foreigners were over-utilising the free health services. According to the participants, foreigners knew that the health services were free and collected treatment (especially chronic treatment) from different clinics so that they would last them longer, since they could only enter South Africa twice a year to get treatment. This was expressed as follows:

'They know that treatment is free and they collect two months' supply, especially the chronic cases; then they go to the next clinic, collect another two months' supply until the client has enough to go back home and stay for plus-minus six months'.

'We have clients that come for their chronic treatment from other countries, crossing the borders and overloading the services.' (Majority of Participants, Females/Registered nurses/Ages of experience ranged from 6-30 years)

After introduction of the free health services policy for PHC services in 1996 a survey was conducted to review South Africans' experiences of free maternal health care and its impact. The results revealed that introduction of the policy led to the abuse of services, with clients collecting drugs with the intention of selling them. It was indicated that foreigners would come into SouthAfrica and utilise the free services 
(Schneider \& Gilson 2000:89; Ijumba 2002:185; Leon et al. 2002:318).

\section{Clients selling medicines}

The following emerged as themes: foreigners collecting medicine in order to sell to others at their homes, and TBpositive patients selling positive sputum as a way of others getting a social grant. The participants voiced their concerns that foreigners were selling treatment and TB-positive sputum to uninfected individuals to allow them to qualify for a grant from the State:

'Yes, the other factor is that clients will come over and over again to collect medicines and sell them outside. When you find out that they sell the medications, they change the clinic'.

'Yes, they collect medications from several clinics around here and they go and sell outside South Africa in the neighbouring countries.' (Four Participants, Females/Registered nurses/Ages of experience ranged from 6-30 years)

The abuse of services and other problems related to free health services have been documented in various studies. In some cases patients sell treatment and those suffering from TB sell their TB-positive sputum to allow access to social grants to those unaffected by TB (Ijumba 2002:185; Schneider \& Gilson 2000:89). The escalating dual epidemics of HIV and AIDS and TB put a burden on the health services, and utilisation of clinics is high (Ijumba 2002:182). The link between TB and HIV has been noted and documented, with almost $50 \%$ of HIVpositive clients developing TB, thus increasing the incidence of TB infections (Uys \& Cameron 2003:3). Mugyenyi (2007:1) confirms that it is conservatively estimated that about $60 \%$ of clients presenting with TB symptoms are also infected with $\mathrm{HIV}$, thus making it difficult to manage the TB infection. The incidence of coinfection has increased due to clients selling TB-positive sputum to the uninfected so they can qualify for a grant.

\section{Poor adherence to PMTCT}

The following themes were identified here: HIV-positive clients on the PMTCT programme not complying with the use of baby formula, confidentiality and stigmatisation as problems, and family and community cultural practices and queries on breast-feeding.

The participants said that clients who were put on the PMTCT programme did not comply with the use of the infant feeding formula due to stigma from the community and cultural expectations:

'With PMTCT you can never be sure. Most of them are provided with PMTCT in the labour ward and some still behave as if they do not know anything'.

'Confidentiality and stigmatisation is a problem'.

'Maybe it's the pressure from the family, the stigma from the family and the expectations from the family and community - if she gives the baby a bottle and they prefer just to give the baby the breast.' (Majority of Participants, Females/Registered nurses/Ages of experience ranged from 6-30 years)

Several studies have been conducted on the effect of stigma on provision of health services. These confirmed that societal stigma was a limiting factor in primary and secondary prevention of HIV and care (Botma et al. 2007:48; Shapiro et al. 2003:201; Greeff \& Phetlhu 2007:13).

The PMTCT programme was introduced in all facilities following a court order, with certain standards set by the WHO. One of these principles was that HIV-positive women were to be counselled about their choices regarding baby feeding, and supported regardless of which option they chose (Peltzer et al. 2005:27). In the Gauteng Province the provision of PMTCT was implemented as early as 2001, starting with piloted sites, but now the service has been expanded to many other facilities (Kenyon, Heywood \& Conway 2002:161).

A study conducted in Botswana supported the perception that, as a result of the stigma of HIV and AIDS, HIV-positive women may choose to avoid disclosing their status by feeding according to traditional practices. This may have led to some women in this study breast-feeding their baby rather than using infant feeding formula (Shapiro et al. 2003:201). Contrary to these findings are those of a study conducted by Peltzer et al. (2005:59), which reveals that mothers-in-law did not have a negative impact, but indicated that they knew that HIV could be passed on to the child through breast-feeding, and that they encouraged their children to go for HIV testing.

\section{Service-related factors}

The following subcategories were identified within this category: involvement of health promoters affecting trust and confidentiality, competing of programmes, lack of continuity of care, and lack of security in clinics.

\section{Involvement of health promoters}

One theme was identified in this subcategory: the involvement of health promoters as volunteers affecting trust and confidentiality. This was expressed as follows:

'With regard to what has been practised, with VCT, we realise that the health promoters are being used for counselling the clients and thereafter the registered nurse will come and prick. After pricking, a different health promoter will divulge the results.' (Majority Participants, Females/Registered nurses/ Ages of experience ranged from 6-30 years)

According to the Gauteng DoH Strategic Plan 2004-2006, the strengthening of community participation and the community health worker programmes were implemented to create a unit of volunteers with standard skills for community-based care (Gauteng DoH 2004-2006:66). The training of community health workers has been conducted in the province with the help of NGOs, and a career path developed to train them further. The involvement of community members enables the community to make informed decisions and participate in the management of their health (Hattingh et al. 2006:51). In a study conducted by Peltzer et al. (2005:37) HIV-positive clients expressed appreciation for the involvement of health promoters.

\section{Competing of programmes}

Two themes emerged within this subcategory: programmes (such as the EPI and IMCI) are not regarded as important, and HIV and AIDS are given first preference. 
The participants felt that programmes such as EPI and IMCI, which were introduced in the clinics, required a lot of training. The perception was that some programmes had been given more attention, whilst the EPI and IMCI were not regarded as important:

'Yes, I think another challenge will be competing of programmes; we have many programmes like the mother and child, with a manager for EPI and manager for IMCI'.

'You cannot compete with HIV and TB actually and sometimes such programmes as EPI suffer because they are just taken as a normal strategy.' (Four Participants, Females/Registered nurses/Ages of experience ranged from 6-30 years)

A survey report by WHO and UNICEF (2003:103) indicated that IMCI, EPI and PMTCT programmes as components of mother and child health need to be integrated with nutrition and other strategies in order to ensure the survival of children. The Gauteng DoH Strategic Plan 2004-2006 also identifies the integration of these programmes with the PMTCT programme as a means of fighting the HIV pandemic (Gauteng DoH 2004-2006:90).

The participants perceived that HIV and AIDS are a challenge to health which also contributed to the problems with service delivery, since more training and updating of knowledge were needed in order to deal with the HIV pandemic. This led to some professionals involved in other programmes, such as EPI and IMCI, having feelings of inferiority. In a study conducted by Masilela, Molefakgotla and Visser (2001:242) district managers emphasised the importance of the integration of programmes at provincial level in order to avoid programmes that are introduced in the services and implemented independently from other services in the clinics, causing problems with implementation. The managers felt that they were bombarded with a lot of vertical programmes in the healthcare services.

\section{Lack of continuity of care}

The one theme that emerged from this subcategory is that of clients moving from one clinic to another. Followup consultations with such clients were difficult, as they returned to their homes and subsequently attended clinics nearby. Some clients also gave false addresses, making it difficult to follow up with them:

'Some clients move from one clinic to the other around our villages, especially those with STIs [sexually transmitted infections], and VCT and follow-up is difficult'.

'Patients give wrong addresses and it is difficult to follow them up ... the reason is that they sell the medicine.' (Majority of Participants, Females/Registered nurses/Ages of experience ranged from 6-30 years)

The management of clients in the clinics is guided by certain protocols and guidelines, as prescribed in the essential drug list. The guidelines on the management of STIs prescribe that clients must have a follow-up consultation, and also advocate treatment of the partner. The continuity of treatment is affected by the difficulty in following up with clients. Movement of clients between clinics was confirmed as resulting in a lack of continuity of care. Client-held records are a way of ensuring continuity of care when users find themselves in a clinic in an area other than that which they normally use (Heunis et al. 2006:44).

\section{Lack of security in clinics}

One theme was formulated in this subcategory: security breaches by clients. The participants expressed fear of lack of security and protection from clients. They explained that some clients passed through the security gates and came into the consulting room with guns:

'The security at our clinic is very poor ... clients come with guns and they pass through security offices freely.' (Five Participants, Females/Registered nurses/Ages of experience ranged from 6-30 years)

Security in health facilities remains a concern; it has to cover both the clients and the health providers. Hattingh et al. (2006:66) state that only safety for the client has been ensured through the utilisation of properly qualified and trained professional nurses. However, safe care cannot be rendered in overcrowded healthcare facilities. Facility managers' concerns about lack of security and crime have been documented by Leon et al. (2002:218), who highlight concerns about hijacking, stolen cars, stolen babies and threatening of staff in facilities. Ijumba (2002:193) confirmed that nurses are three times more likely to experience crime and violence in the workplace than other occupational groups.

\section{Solutions to problems}

Solutions to problems emerged as the fifth category, with the following perceived as solutions to the factors affecting service delivery that the participants identified: integration of services, electronic record-keeping and strengthening of support groups.

\section{Integration of services}

The integration of HIV and AIDS services with mother and child services was identified as one of the solutions. The participants felt that the programmes that are being expanded could be integrated, with one person coordinating all of them. This would be beneficial, especially in the case of the integration of HIV and AIDS and mother and child health services:

'Isolation of certain services poses a problem'.

'Integration of IMCI would enable the nurse to identify immunisation problems or needs and also the EPI would refer to $\mathrm{IMCI}^{\prime}$.

'Integration of PMTCT to all mother and child health services, even IMCI, could make the services be more comprehensive.' (Majority of Participants, Females/Registered nurses/Ages of experience ranged from 6-30 years)

The integration of the IMCI strategy into PHC services has been planned from the introductory phase, because it was regarded as a survival strategy for children and had to be integrated with other survival strategies. The WHO and UNICEF (2003:21) reported that IMCI advocates the coverage of all missed opportunities in immunisation, which points toward the integration of IMCI and EPI. The survey identified a shortage of vaccines, power cuts and a 
lack of segregated refrigerators as constraints to service delivery which impacted negatively on the effectiveness of immunisation services (WHO \& UNICEF 2003:22). The survey further recommended integration with other services, starting with coordination at national and provincial level to ensure that all programmes and training courses are linked during training, including $\mathrm{HIV}$ and AIDS programmes (WHO \& UNICEF 2003:26).

\section{Electronic record-keeping}

The following themes were formulated in this subcategory: management of XDR-TB; use of technology in MOUs for fetal monitoring graphs; use of technology to prevent clients from having more than one file in one clinic; use of identity document numbers in the clinics, with all clinics linked to one system and database; use of technology to control drugs dispensed to clients to avoid double collection in one month from different clinics; use of technology to fast-track the management of clients in different programmes being expanded; and use of technology to curb health-facility shopping by clients. These were expressed as follows:

'There is an urgent need to initiate technology in our services ... managing extreme drug-resistant tuberculosis'.

'Fetal monitoring could also improve quality of care'.

'Technology can help that if a patient gets to one clinic he is captured in the system that will reveal him when he gets to the other clinic that he has been given treatment at such a clinic'.

'The ID can also help if all the clinics are linked to one system, most of the duplication of services by clients cannot be there anymore because the client will be seen immediately'.

'Using computers to keep patient data would help fast-tracking the management of clients.' (All the Participants, Females/ Registered nurses / Ages of experience ranged from 6-30 years)

The need for technology in these times of increasing demands on the health sector is crucial. In all planning the emphasis should be on equipment and material, including availability of skilled nurses. It is also important to consider the acceptability of technology to both clients and healthcare providers, including the cost of computerising records to healthcare providers (Hattingh et al. 2006:123). Change is the order of the day, and new technology, electronic workstations and internal communication networks will change the healthcare environment and subsequently the training of staff.

\section{Strengthening of support groups}

The following theme was formulated in this subcategory: strengthening of the available support groups to include other essential services such as nutrition and current programmes being expanded. The participants acknowledged the presence of support groups in the community and other services, and felt strongly that these groups should be strengthened:

'We need to strengthen the support groups to meet the needs of various groups of patients ... nutrition groups, breast-feeding groups and mental health groups'.

'We should create more awareness about the usability and user-friendliness of our programmes.' (Majority of Participants,
Females/Registered nurses/Ages of experience ranged from 6-30 years)

Botma et al. (2007:48) state that the greatest barrier to VCT is the fear of a positive diagnosis, but also report that people would go for VCT if they could count on support from the community. This supports the strengthening of communitybased support groups for people living with HIV. Kenyon et al. (2002:203) document a study by Modiba et al. (2001:192) in which service users were interviewed, and affected clients revealed that they belonged to a support group as a way of preventing boredom.

\section{Healthcare worker training}

The following themes were formulated under this subcategory: upgrading of trained nurses, especially the older nurses, on expansion programmes on a continual basis, and skills development for nurses on the expanded programmes to allow for rotation of staff and continuity of care. Emphasis was placed on training of more nurses in primary mental health. The participants felt that with the introduction of these programmes it was important to conduct ongoing inservice training for all nurses in the service:

'Nurses need to be upgraded in their skills by means of inservice training'.

'Courses in the primary healthcare services need to be updated ... PMTCT, IMCI and others'.

'We need to skill all the nurses so that they could rotate in all the services because this is comprehensive health care ... we continue skilling them every day.' (Majority of Participants, Females/Registered nurses/Ages of experience ranged from 6-30 years)

Heunis et al. (2006:44) state that nurses should be trained in numerous key programmes in order to be able to implement the PHC package effectively. Nursing service managers experienced a lack of training for health workers because bursaries and study leave were difficult to obtain. The lack of own professional development hindered the managers in managing the service effectively, as they needed to acquire the necessary competencies for effective change management (Buys \& Muller 2000:53).

\section{Community education}

The following theme was identified in this subcategory: use of clinic committee members to educate the community on health service operational issues and create awareness of available services:

'Clinics committees must be reintroduced for better participation'

[Majority of Participants, Females/Registered nurses/Ages of experience ranged from 6-30 years].

In a study conducted by Heunis et al. (2006:39) the use of clinic committees was motivated as a good strategy to invite community participation. Heunis et al. (2006:44) state that community participation is an essential pillar of PHC and can be effected through clinic committees. Informing the community about the operational hours of clinics is one of the aspects of the Batho Pele principles introduced by the Department of Public Service and Administration in 1997 to guide the health services of South Africa. 
In their study of the factors that influence PMTCT, Peltzer et al. (2005:39) concluded that family and community support should be improved through peer support groups and training of community counsellors. This could also be done by fostering couple and community discussions. Botma et al. (2007:53) suggest that in order to integrate topics on HIV and AIDS into the education of the community, the community needs to be educated on parental and school guidance.

\section{Recommendations}

Based on the results of the study, further research on the effects of the shortage of skills and lack of space on integration of the expansion programmes in the PHC setting is recommended

It is important that comprehensive basic training of nurses on the expansion programmes related to mother and child health and HIV and AIDS is included in the curriculum.

Further research should be conducted on the actual effects of factors related to inadequate skills on the quality of service delivery.

\section{Limitations of the study}

When identifying the inclusion criteria, the researcher was aware of other categories of health professionals and PHC workers who were excluded from the study.

\section{Conclusion}

It is clear from the findings of this study that the factors that affect service delivery in a PHC setting are interrelated and have a negative impact on quality of care. The objective of this study was to explore and describe the perceptions of nurses regarding the factors influencing service delivery in programmes being expanded in a PHC setting. Based on the findings of the study, it can be concluded that the objective of the study has been achieved. It is hoped that measures will be put into place to control and monitor these factors in order to improve service delivery in the PHC environment. The following recommendations were made:

- Integration of services should include training on child survival strategies such as the IMCI strategy and EPI, together with the PMTCT programme.

- Training for these expansion programmes should be integrated so as to release one nurse who will be comprehensively trained on all the programmes, to reduce the problem of releasing staff.

- Services such as family planning should be extended to weekends and after-hours for clients who work or attend school.

\section{Acknowledgements}

The following are acknowledged for their contributions towards the success of this paper: the University of Pretoria, Gauteng Provincial Department of Health, Tshwane District health service and the PHC nurses.

\section{Competing interest}

The authors declare that they have no financial or personal relationship(s) which may have inappropriately influenced them in writing this article.

\section{Contribution to the field}

This article adds to the body of knowledge in the PHC field and the improvement of service delivery.

\section{References}

African National Congress, 1994, Reconstruction and development program, Umanyano, Johannesburg.

Allen, R.C., 1990, The Concise Oxford Dictionary of Current English, 8th edn., Oxford University, NY.

Botma, Y., Motiki, Z.D. \& Viljoen, M.C., 2007, 'Learners' knowledge and perceptions of voluntary counseling and testing for HIV \& AIDS in the Free State Province', Curationis 30(2), 48-57.

Brink, H., Van der Walt, C. \& Van Rensburg, G., 2006, Fundamentals of research methodology for health professionals, 2nd edn., Juta, Pretoria.

Buys, R. \& Muller, M., 2000, 'The experiences and perceptions of nursing service managers regarding transformation of health services in selected provincial academic health complexes', Curationis 23(2), 50-56.

Carson, V.B., 2000, Mental health nursing: The nurse-patient journey, 2nd edn., W.B. Saunders, Tokyo.

Cormack, D.F.S., 2000, The research process in nursing, 4th edn., Blackwell Science, Boston.

Creswell, J.W., 1994, Research design: Qualitative and quantitative approaches, Sage, Thousand Oaks.

De Haan, M., Dennill, K. \& Vasuthevan, S., 2005, The health of southern Africa, 9th edn., Juta Academics, Pretoria.

Dennill, K., King, L. \& Swanepoel, T.T., 1999, Aspects of primary health care: Community healthcare in South Africa, 2nd edn., Oxford University Press, London.

Department of Health, 1996, Department of Health policy: Restructuring the national healthcare system for universal primary healthcare, Government Printers, Pretoria.

Department of Health, 2001, Comprehensive primary healthcare service package for South Africa, Government Printers, Pretoria.

De Vos, A.S., Strydom, H., Fouché, C.B. \& Delport, C.S.L., 2005, Research at grassroots For the social science and service professions, 3rd edn., Van Schaik, Pretoria.

Gauteng Department of Health, 2004-2006, The Gauteng Health Strategic Plan, Programme 2: District Health Services report document, Government Printers, Pretoria.

Greeff, M. \& Phetlhu, R., 2007, 'The meaning and effect of HIV/AIDS stigma for people living with AIDS and nurses involved in their care in the North West Province, S.A.', Curationis 30(2), 12-23.

Hattingh, S.P., Dreyer, M. \& Roos, S., 2006, Aspects of community health, 3rd edn., Oxford University Press, Cape Town.

Heunis, J.C., Van Rensburg, H.C.J. \& Claassen, D.L., 2006, 'Assessment of the implementation of the primary healthcare package at selected sites in South Africa', Curationis 29(4), 37-46. PMid:17310743

Ijumba, P., 2002, Voice of primary healthcare facility workers, South African Health Review, Health Systems Trust, Durban.

Kenyon, C., Heywood, M. \& Conway S., 2002, 'Mainstreaming HIV and AIDS: Progress and challenges', in SA Health Review, University of Witwatersrand/Health Systems Trust, Johannesburg.

Leon, N., Bhunu, F. \& Kenyon, C., 2002, Voices of facility managers, South African Health Review 2002, Health Systems Trust, Johannesburg.

Lincoln, Y.S. \& Guba, E.G., 1985, Naturalistic inquiry, Sage, Lendos.

Masilela, T., Molefakgotla, P. \& Visser, R., 2001, 'Voices of district managers', in South African Health Review 2001, University of the Witwatersrand/Health Systems Trust, Johannesburg.

Mashego, T. \& Peltzer, K., 2005, 'Community perceptions of quality of care (primary) healthcare services in a rural area of Limpopo Province, South Africa: A qualitative study', Curationis 28(2), 13-21.

Meyer, K., Heunis, C., Janse van Rensburg-Bonthuyzen, E., Engelbrecht, M. \& Summerton, J., 2003, PHC delivery in the Alexandra urban renewal site, Gauteng: Mapping gaps in the maternal health, IMCI, TB, STI's, HIV \& AIDS and EDL programmes, Centre for Health Systems Research \& Development, Bloemfontein.

Modiba, P., Gilson, L. \& Schneider, H., 2001, Voices of service users, South African Health Review, Health Systems Trust, Johannesburg.

Mugyenyi, P., 2007, 'Collaboration to kill: HIV/AIDS and TB, Science and Development Network', viewed 30 June 2008, from, http://www.scidev.net/en/opinions/ collaboration-to-kill-hivaids-and-tb.html 
Muller, M., 2000, 'The quality of Nursing Management in South African Hospitals', Curationis 10(1), 63-69.

Netshandane, V.O., Nemathaga, L. \& Shai-Mahoko, S.N., 2005, 'Experiences of primary healthcare nurses regarding the provision of the healthcare services in the northern region of the Limpopo Province', Curationis 28(1), 59-68. PMid:15850154

Peltzer, K., Skinner, D., Mfecane, S., Shisana, O., Nqeketo, A., Mosala, et al., 2005 Factors influencing the utilization of prevention of mother-to-child-transmission (PMTCT) services by pregnant women in the Eastern Cape, Health SA Gesondheid 10(1), 26-40.

Polit, D.F. \& Beck, C.T., 2006, Essentials of nursing research: Methods, appraisal and utilization, 6th edn., Lippincott Williams \& Wilkins, London.

Polit, D.F. \& Hungler, B.P., 1995, Nursing research: Principles and methods, 5th edn., J.B. Lippincott Company, London.

Rall, M. \& Meyer, S.M., 2006, The role of the registered nurse in the marketing of primary healthcare services as part of health promotion, Curationis 29(1), 10-24. PMid:16817488
Schneider, H. \& Gilson, L., 2000, Review of South African experiences of free materna healthcare and its impact on maternal health, Centre for Health Policy, University of the Witwatersrand, Johannesburg.

Shapiro, R.L., Lockman, S., Thior, I., Stocking, L., Kebarabetswe, P., Wester, C., et al., 2003, 'Low adherence to recommended infant feeding strategies among HIVinfected women: Results from the pilot phase of a randomized trial to PMTCT in Botswana', AIDS Education and Prevention 15(30), 201-230.

Tesch, R., 1990, Qualitative research: Analysis, types and software tools, The Falmer Press, Bristol, PA.

Uys, L. \& Cameron, S., 2003, Home-based HIV and AIDS care, Oxford University Press, Cape Town.

Van Rensburg, H.C.J., 2004, Health and health care in South Africa, Van Schaik, Pretoria.

Welman, C., Kruger, F. \& Mitchell, B., 2005, Research methodology, 3rd edn., Oxford University Press, NY.

World Health Organisation \& United Nations Children's Fund, 2003, Report of IMC health facility survey in Gauteng Province conducted in July 2002, Department of Health, Pretoria. 